\title{
Do obstructive sleep apnea syndrome patients underestimate their daytime symptoms before continuous positive airway pressure treatment?
}

\author{
Gabrielle Leclerc, Yves Lacasse MD, Diane Page RN, Frédéric Sériès MD
}

G Leclerc, Y Lacasse, D Page, F Sériès. Do obstructive sleep apnea syndrome patients underestimate their daytime symptoms before continuous positive airway pressure treatment? Can Respir J 2014;21(4):216-220.

BACKGROUND: Daytime somnolence is an important feature of the obstructive sleep apnea (OSA) hypopnea syndrome and is usually subjectively assessed using the Epworth Sleepiness Scale (ESS).

OBJECTIVE: To compare the scores of the ESS and different domains of the Quebec Sleep Questionnaire (QSQ) assessed before and after the first months of continuous positive airway pressure (CPAP) treatment, as well as retrospectively without treatment.

METHODS: The ESS score and domain scores of the QSQ were obtained before and after a three-month period of CPAP treatment using a retrospective assessment of the pretreatment scores in 76 untreated OSA patients.

RESULTS: Fifty-two patients completed the study. The ESS and QSQ scores significantly improved following CPAP therapy. Retrospective evaluation of the ESS score was significantly worse than pre- and posttreatment values (mean $[ \pm \mathrm{SD}$ ] pretreatment score $11.0 \pm 4.8$; retrospective pretreatment score 13.5 \pm 5.1 ). Such differences were not observed in any domain of the QSQ, including the domain assessing hypersomnolence. CONCLUSION: OSA patients underestimated their sleepiness according to the most widely used instrument to assess hypersomnolence. This finding may not be observed with other methods used to assess OSA-related symptoms such as quality of life questionnaires.

Key Words: Daytime somnolence; Quality of life

$\mathrm{O}$ bstructive sleep apnea (OSA) is characterized by recurrent episodes of partial or total upper airway obstruction, accounting for hypopneic or apneic events during sleep. These breathing disturbances lead to sleep fragmentation, alteration of sleep structure and repetitive nocturnal desaturations. The OSA syndrome (OSAS) is defined as the coexistence of unexplained excessive daytime sleepiness with at least five obstructed breathing events (apnea or hypopnea) per hour of sleep (1). OSAS may account for numerous clinical complaints such as fatigue, excessive tiredness, depressive mood and loss of interest in socializing (2). Therefore, aside from the recognized consequences of OSA, such as vigilance (3) and cardiometabolic risk (4,5), it also has an important impact on quality of life (QoL). In fact, the impact of sleep apnea on QoL has been reported in several studies (2-6). In evaluative QoL questionnaires, the main complaints identified by OSAS patients can be grouped into five major domains including daytime hypersomnolence, emotional function, social interactions, and diurnal and nocturnal symptoms that characterize QoL alteration in OSAS $(2,6)$. The benefits of treatment such as continuous positive airway pressure (CPAP) therapy on $\mathrm{QoL}$ have been well documented $(7,8)$. However, it is frequently observed that patients only realize the real impact of OSAS on their QoL after treatment initiation. This may be related to the fact that such impairments could be present for years before OSAS has been diagnosed or treated. This issue is highly clinically relevant because a lack of symptoms reported by OSAS
Les patients atteints d'un syndrome d'apnée obstructive du sommeil sous-estiment-ils leurs symptômes diurnes avant la ventilation en pression positive continue?

HISTORIQUE : La somnolence diurne, une caractéristique importante du syndrome d'apnée(-hypopnées) obstructives du sommeil (AOS), est habituellement évaluée de manière subjective au moyen de l'échelle de somnolence d'Epworth (ESE).

OBJECTIF : Comparer les indices de l'ESE et évaluer divers domaines du questionnaire du sommeil de Québec (QSQ) avant et après les premiers mois de traitement par ventilation en pression positive continue (VPPC), ainsi que rétrospectivement sans traitement.

MÉTHODOLOGIE : Les chercheurs ont obtenu l'indice d'ESE et les indices de domaines du QSQ avant et après une période de traitement par VPPC au moyen d'une évaluation rétrospective des indices obtenus avant le traitement chez 76 patients faisant de l'AOS non traitée.

RÉSULTATS : Cinquante-deux patients ont terminé l'étude. Les indices d'ESE et de QSQ se sont considérablement améliorés après le traitement par VPPC. L'évaluation rétrospective de l'indice d'ESE était beaucoup plus négative que les valeurs avant et après le traitement (indice moyen [ \pm ÉT] avant le traitement de $11,0 \pm 4,8$; indice rétrospectif avant le traitement de $13,5 \pm 5,1)$. Les chercheurs n'ont observé de telles différences dans aucun des domaines du QSQ, y compris le domaine évaluant l'hypersomnolence. CONCLUSION : Les patients faisant de l'AOS sous-estimaient leur somnolence d'après l'instrument le plus utilisé pour évaluer l'hypersomnolence. Cette constatation n'est pas nécessairement reproduite avec d'autres méthodes utilisées pour évaluer les symptômes liés à l'AOS, tels que les questionnaires sur la qualité de vie.

Unité de recherche en pneumologie, Centre de recherche, Institut Universitaire de cardiologie et de pneumologie de l'Université Laval, Université

Laval, Quebec City, Quebec

Correspondence: Dr Frédéric Sériès, Centre de Pneumologie, Institut Universitaire de Cardiologie et de Pneumologie de Québec, 2725 chemin

Sainte-Foy, Québec G1V 4G5. Telephone 418-656-4747, fax 418-656-4762, e-mail frederic.serie@@med.ulaval.ca 


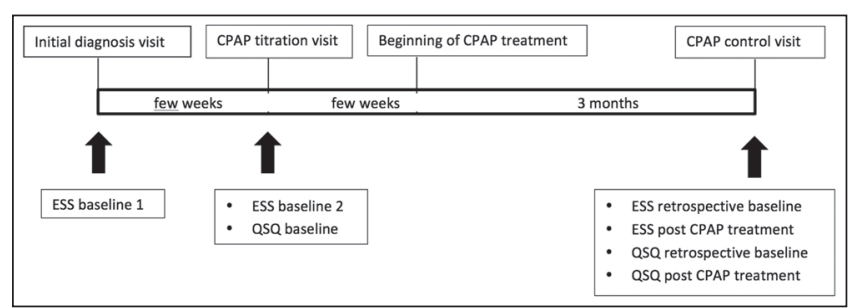

Figure 1) Time line reporting the respective time of administration of the two different questionnaires (Epworth Sleepiness Scale [ESS] and Quebec Sleep Questionnaire [QSQ]) over time. CPAP Continuous postive airway pressure

cardiorespiratory home sleep recording or by in-laboratory polysomnography. Subsequently, treatment alternatives were discussed with each patient. Participation in the study was offered to those who underwent CPAP therapy from February to July 2011.

\section{CPAP titration and follow-up}

A titration procedure (manual or automatic) was completed to determine the effective positive pressure level. Manual CPAP titration was performed in a sleep laboratory, with pressure level being raised by a technician during the night until apneas, hypopneas and snoring had disappeared (11). Automatic CPAP titration was completed using a portable monitoring device used for one to three nights at home. This device adjusted the pressure level needed to normalize nocturnal breathing throughout the night; the effective CPAP pressure was established as the 90th or 95th percentile of applied pressure level depending on the automatic CPAP device. Then, an automatic or a continuous standard pressure was prescribed to each patient. Thereafter, treated patients received a follow-up telephone call from the nurse of the sleep clinic of IUCPQ within the first four weeks of treatment to complete all adjustments that could improve treatment efficiency/adherence (12). Additional follow-up calls were performed to solve any problems reported by patients during the first three months. A control medical appointment was scheduled at the end of the first three months of treatment to assess clinical evolution and treatment efficacy (CPAP observance report, apnea-hypopnea index [AHI] according to the download of the report from CPAP machine).

\section{QoL questionnaire}

The QSQ was administered. The QSQ consists of 32 questions assessing QoL through five domains: hypersomnolence, diurnal symptoms, nocturnal symptoms, emotions and social interactions. This questionnaire has previously been found to provide a valid measure of healthrelated QoL in patients with OSA and is sensitive to treatment-induced changes (13).

\section{ESS}

The ESS was administered to specifically evaluate subjective daytime hypersomnolence. It consists of a self-administered questionnaire that evaluates the risk of falling asleep in eight different daytime life situations (14).

\section{Protocol}

The ESS was completed four times: twice before treatment (at the initial diagnosis and CPAP titration visits) to quantify the score variability overtime; and twice at the three-month CPAP control visit (assessment of post-treatment score and retrospective measurement of pretreatment hypersomnolence) (Figure 1).

The QSQ was administrated at two different visits: at the CPAP titration visit and at the three-month control visit. At this last visit, patients completed the questionnaire to assess their QoL status while treated and retrospectively while untreated. The QSQ was completed only once before treatment due to technical reasons. The project was initiated because patients may have already completed their first clinical assessment as well as their diagnosis sleep recording. The ESS is

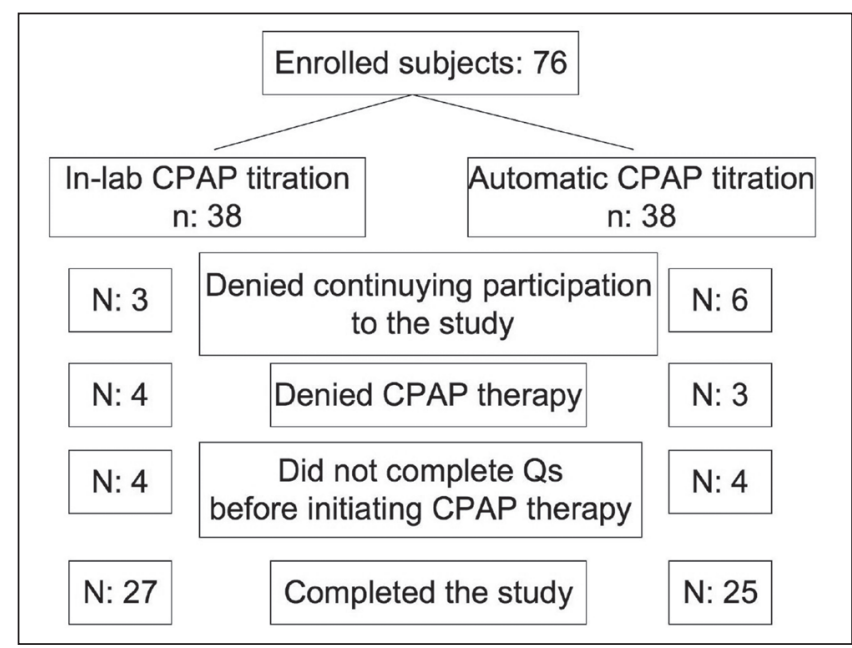

Figure 2) Flow chart of the study. CPAP Continuous positive airway pressure; Qs Questionnaires

systematically completed at each visit (even outside any research project), which is not the case for the QSQ. The pretreatment QSQ was subsequently completed at the CPAP titration visit only when patients agreed to participate in the present study. It should be noted that each questionnaire was completed with the subjects blinded to baseline results.

\section{Statistic methods}

A one-way ANOVA repeated measures analysis was used with HolmSidak method and Dunn's Method for all pairwise multiple comparison procedures to compare QSQ scores and ESS scores before, retrospectively and post-treatment. The Spearman rank order test was used to establish correlations between the ESS and QSQ hypersomnolence domain, and the Pearson product-moment correlation coefficient was used between the same questionnaire's scores at different moments (before, retrospective, post) to assess test-retest reliability.

\section{Patients}

\section{RESULTS}

A flow chart of the study is presented in Figure 2. Seventy-six patients participated in the study and 52 completed the study. These patients were divided into two groups: a manual titration group $(n=27)$ and an automatic titration group $(n=25)$. The mean $( \pm S D)$ effective pressure level was $9.8 \pm 2.2 \mathrm{cmH}_{2} \mathrm{O}$. Thereafter, five patients were treated with automatic CPAP and 47 with conventional fixed CPAP. AHI values provided by CPAP machines' reports were normal $(2.4 \pm 2.2$ events/h). This report also indicated adequate observance (duration of use per day: $377 \pm 103 \mathrm{~min}$; percentage of nights with $>4$ h of use: $90.7 \pm 30.8 \%$ ). Twenty-four patients did not complete the study (eight did not complete the first questionnaire before starting treatment; nine others decided not to complete the study and did attend their control visit; and seven patients decided not to start CPAP therapy). The dropout group was similar to the treatment group for anthropometric characteristics, with no difference in diagnosis procedure (ie, home cardiorespiratory monitoring/oximetry versus in-laboratory polysomnographic recording) nor in apnea severity between dropouts and patients who completed the study (Table 1).

\section{ESS}

The scores of the two pretreatment questionnaires did not differ significantly, with a good test-retest reliability $(r=0.63)$. Seventeen percent of the subjects had a difference $\geq 5$ between the two pretreatment scores. Post-treatment ESS results significantly improved at the three-month visit, with no difference in improvement between the two CPAP titration modes. The retrospective evaluation of diurnal 
TABLE 1

Characteristics of patients who participated in the study compared with those who dropped out

\begin{tabular}{lccc}
\hline Characteristics & Dropouts & Participants & P \\
\hline Patients, $\mathrm{n}$ & 24 & 52 & \\
Age, years & $53.8 \pm 9.7$ & $52.8 \pm 10.4$ & 0.72 \\
Sex, female/male, $\mathrm{n} / \mathrm{n}$ & $9 / 15$ & $17 / 52$ & 0.82 \\
Body mass index, $\mathrm{kg} / \mathrm{m}^{2}$ & $32.4 \pm 6.2$ & $31.6 \pm 5.8$ & 0.74 \\
Neck circumference, cm & $41.3 \pm 4.7$ & $40.6 \pm 5.0$ & 0.64 \\
Diabetes, $\mathrm{n}$ & 7 & 10 & 0.34 \\
Arterial hypertension, $\mathrm{n}$ & 9 & 19 & 0.96 \\
Ambulatory diagnosis, \% & 50 & 54 & 0.65 \\
Respiratory distress index, events/h & $31.8 \pm 13.8$ & $28.4 \pm 14.1$ & 0.40 \\
In-laboratory diagnosis, \% & 50 & 46 & 0.65 \\
Apnea-hypopnea index, events/h & $38.1 \pm 25.6$ & $38.7 \pm 24.1$ & 0.81 \\
Pretreatment scores & & & \\
Epworth Sleepiness Scale & $12.2 \pm 4.8$ & $11.0 \pm 4.8$ & 0.28 \\
Nocturnal symptoms, au & $3.7 \pm 1.1$ & $3.8 \pm 1.3$ & 0.71 \\
Diurnal symptoms, au & $3.5 \pm 1.3$ & $3.3 \pm 1.5$ & 0.61 \\
Hypersomnolence, au & $3.8 \pm 1.5$ & $3.8 \pm 1.6$ & 0.96 \\
Emotions, au & $4.4 \pm 1.4$ & $4.1 \pm 1.5$ & 0.56 \\
Social interactions, au & $4.2 \pm 1.3$ & $4.4 \pm 1.4$ & 0.69 \\
\hline
\end{tabular}

Data presented as mean $\pm S D$ unless otherwise indicated. au Arbitrary units

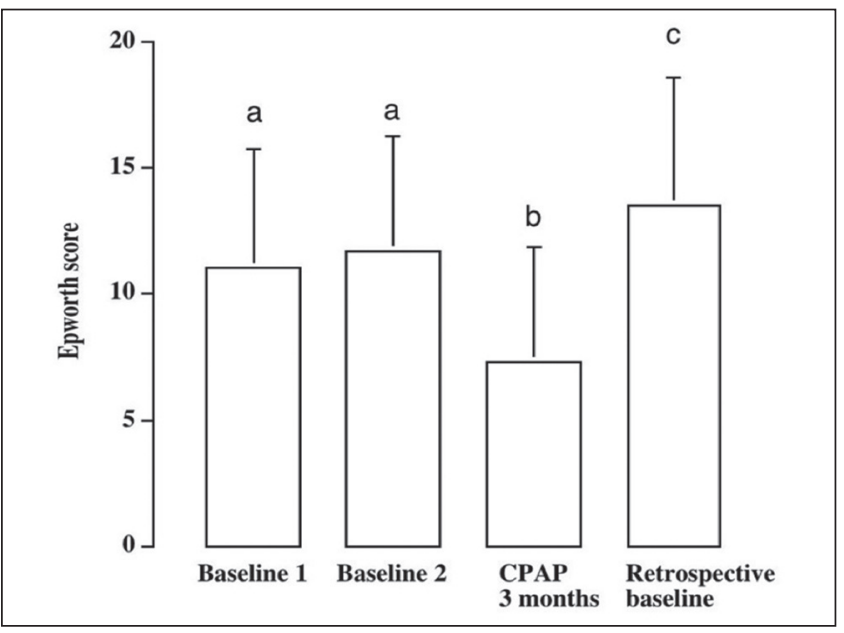

Figure 3) Mean \pm SD values of the values of the Epworth Sleepiness Scale score obtained before continuos positive airway pressure (CPAP) therapy (two occasions), at the end of the first three-month CPAP treatment and retrospectively before treatment. Columns with different letters indicate statistically significant differences

somnolence using the ESS score was significantly worse $(13.5 \pm 5.1)$ compared with pre- $(11.1 \pm 4.8$ and $11.7 \pm 4.6)$ and post-treatment values $(6.9 \pm 4.3)$. Baseline, retrospective pretreatment and post-treatment results were significantly different $(\mathrm{P}<0.001$; except baseline 2 with retrospective pretreatment $[\mathrm{P}<0.01]$ ) (Figure 3). Twenty-one percent $(n=11)$ of patients with an initial score $<10$ at the first baseline evaluation and $13 \%(n=7)$ of patients with a score $<10$ at the second baseline evaluation retrospectively had a score $\geq 10$. Results did not differ when controlling either for average duration of CPAP usage or for AHI while on CPAP. No attempt was made to adjust results depending on diagnostic $\mathrm{AHI}$ because $46 \%$ of the patients were diagnosed using polysomnography and $54 \%$ with cardiorespiratory home testing. A strong correlation was found between baseline and retrospective pretreatment values of the ESS scores $(r=0.74 ; \mathrm{P}<0.001$ with baseline 1 and $r=0.75 ; \mathrm{P}<0.001$ with baseline 2) (Figure 4). In both cases, the intercept of the regression line (retrospective ESS value at a baseline score $=0$ ) was positive ( 4.9 and 3.6 , respectively) and significantly different from 0 .

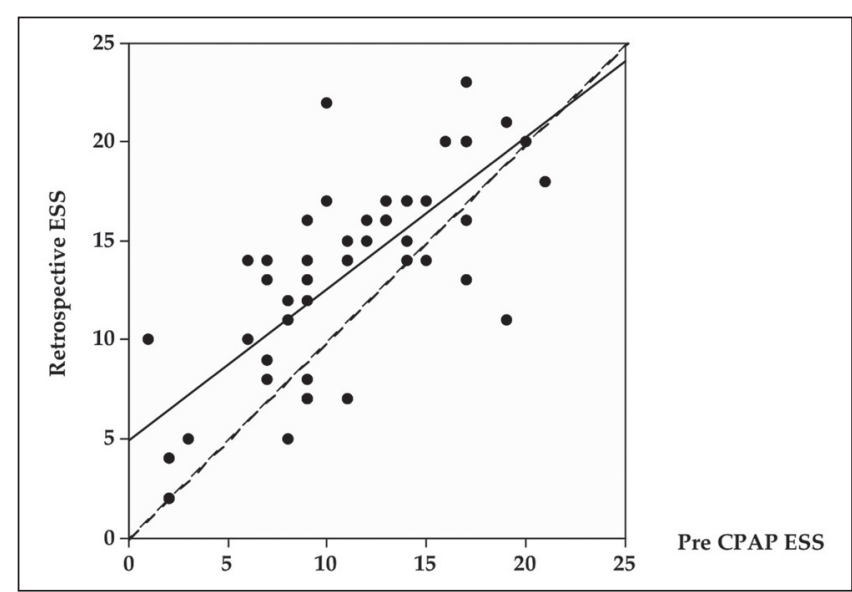

Figure 4) Individual values of the Epworth Sleepiness Scale (ESS) score obtained before treatment (baseline 1) and retrospectively after three months of continuous positive airway pressure (CPAP) therapy. Solid line: $r=0.75$, dashed line: line of identity

\section{QSQ}

A significant improvement in the score of each domain was observed following CPAP therapy, with no influence of titration mode on these results. There was no significant difference in the baseline and retrospective pretreatment scores in any of these domains (Figure 5). In each domain, there was a high correlation between the baseline and retrospective pretreatment results (hypersomnolence $r=0.84$; diurnal symptoms $r=0.86$; nocturnal symptoms $r=0.71$; emotions $r=0.79$; social interaction $\mathrm{r}=0.68$ ).

Comparison of ESS and QSQ hypersomnolence domain scores The QSQ integrates five different domains, with one domain specifically assessing hypersomnolence. The ESS was found to correlate with the QSQ hypersomnolence domain score with the same magnitude as the one observed in the authors' original validation publication (13) (original baseline correlation $=-0.64$; current baseline correlation with pretreatment ESS $=-0.60$ and -0.68 at the two baseline assessments). Significant correlations were found between the scores of the specific questions (Q) of the ESS and those of the QSQ hypersomnolence domain that are very close to one another (ie, hypersomnolence while reading: Q1 ESS and Q31 QSQ; driving: Q8 ESS and Q32 QSQ; and resting in the afternoon: Q5 ESS and Q7 QSQ) (Table 2).

\section{DISCUSSION}

The present study showed that CPAP therapy over a three-month period may change perceptions of pre-CPAP sleepiness. We found that diurnal somnolence at the time of diagnosis using the ESS score is underestimated when compared with its retrospective evaluation following effective treatment of OSA. However, no difference was found in the scores of the different domains of the QSQ before treatment and retrospectively following CPAP therapy. On the other hand, the present results are consistent with those of previous studies examining the improvement in diurnal somnolence and QoL following CPAP therapy.

\section{Titration modes}

No difference was found in the treatment response according to titration mode (automatic versus manual). This can be explained by the fact that in the present study, CPAP compliance was the same in the two groups. In fact, results of a recent meta-analysis (15) suggest that both treatment strategies similarly improve sleep-disordered breathing, sleep fragmentation and QoL. Depending on the study, compliance may be higher by $11 \mathrm{~min}$ per night with the automatic titration mode and the ESS score may improve by 0.5 points; however, the clinical significance of these changes are unknown and such differences were not observed in the present study $(10,15)$. 


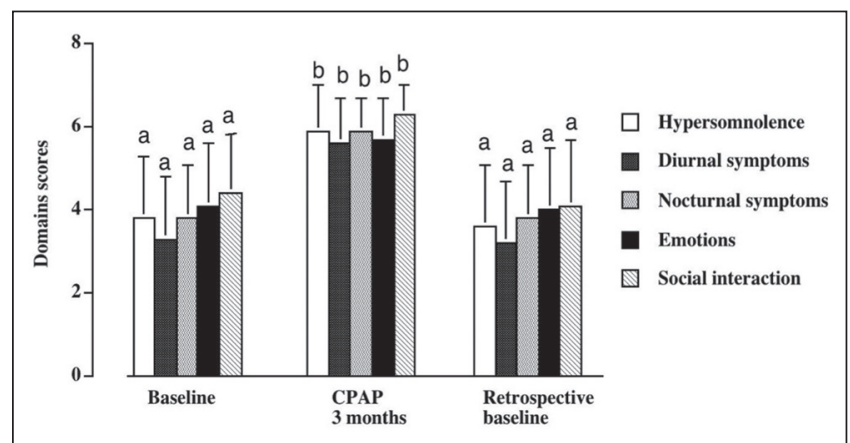

Figure 5) Mean \pm SD values of the different domains of the Quebec Sleep Questionnaire obtained before continuous positive airway pressure (CPAP) therapy, at the end of the first three months of CPAP treatment and retrospectively before treatment. Bars with different letters indicate statistically significant differences

\section{ESS results}

The higher retrospective pretreatment ESS score was noted in the absence of differences between the two pretreatment assessments using the ESS. Moreover, the reliability of the ESS score is supported by the good correlation observed between the two baseline scores. Zimmermann et al (16) found no difference between pretreatment ESS scores and retrospective estimation obtained after one year of CPAP treatment. Even if both studies are similar in terms of sample size, their results do not account for test-retest variability. Chin et al (17) compared ESS scores before and retrospectively after nasal CPAP treatment in 31 OSA patients, and found that patients underestimate diurnal sleepiness before initiating CPAP treatment. However, this retrospective subjective assessment of diurnal somnolence was performed after a longer treatment period (10 months) and daytime sleepiness was only assessed using the ESS. In the study by Chin et al (17), the post-treatment ESS was completed after only one month of CPAP treatment but the retrospective pretreatment ESS assessment was completed nine months later. It can be reasonably asked to what extent a 10-month delay can alter the memory of symptoms of daytime somnolence. In the present study, we demonstrate that this pretreatment underestimation of sleepiness was observed after only three months of CPAP treatment. By completing the post-treatment and retrospective pretreatment questionnaires at the same time, we believe that our patients could more precisely rate the evolution of their symptoms. Furthermore, comparing the retrospective changes in ESS and QSQ scores demonstrate that they provide different dimensions in the assessment of somnolence in addition to other information on QoL. Nguyen et al (18) evaluated pretreatment variability of the ESS by administering it twice before treatment to apneic patients with an average time interval of 71 (92) days. Twenty-three percent of the subjects had a difference of $\geq 5$ points between the two pretreatment scores. In the present study, the retrospective evaluation was made after three months of treatment and baseline/retrospective differences were found to exceed test-retest pretreatment variability.

We found that more than one of five patients whose ESS score before treatment was $<10$ retrospectively evaluated their pretreatment score to be $\geq 10$. At the three-month CPAP control visit, patients mentioned they realized the presence of pre-existing symptoms they did not perceive as such before treatment when assessed using the ESS. Underestimation of daytime sleepiness can contribute to misdiagnosis of OSAS because it is the prominent symptom of sleep apnea syndrome and other daytime complaints, such as diurnal fatigue or lack of energy, are not routinely quantified. In clinical practice, the ESS is usually the only questionnaire used to evaluate the presence and severity of daytime sleepiness, with an ESS score of $\geq 10$ used to define the presence of diurnal sleepiness in numerous studies $(19,20)$.
TABLE 2

Correlation between specific questions (Q) of the Epworth Sleepiness Scale (ESS) and the Quebec Sleep Questionnaire (QSQ)

\begin{tabular}{lccc}
\hline $\begin{array}{l}\text { Correlation between } \\
\text { specific ESS and QSQ }\end{array}$ & $\begin{array}{c}\text { Reading } \\
\text { (Q1 ESS \& }\end{array}$ & $\begin{array}{c}\text { Driving } \\
\text { (Q8 ESS \& }\end{array}$ & $\begin{array}{c}\text { Resting } \\
\text { (Q5 ESS \& } \\
\text { questions }\end{array}$ \\
\hline Q31 QSQ) & Q32 QSQ) & Q7 QSQ) \\
\hline Pretreatment 1 & $r=-0.58$ & $r=-0.42$ & $r=-0.47$ \\
& $P<0.0001$ & $P=0.002$ & $P=0.0007$ \\
Pretreatment 2 & $r=-0.58$ & $r=-0.59$ & $r=-0.48$ \\
Retrospective estimation & $P<0.0001$ & $P<0.0001$ & $P=0.0006$ \\
& $r=-0.71$ & $r=-0.61$ & $r=-0.49$ \\
Post-treatment & $P<0.0001$ & $P<0.0001$ & $P=0.0002$ \\
& $r=-0.72$ & $r=-0.34$ & $r=-0.54$ \\
\hline
\end{tabular}

QSQ and ESS results

The QSQ is a disease-specific QoL questionnaire that focuses on specific domains known to be altered in OSAS patients. It contains five domains: hypersomnolence, diurnal symptoms, nocturnal symptoms, emotions and social interactions. Our results show that CPAP therapy significantly improved the scores of each of the five domains as previously reported in our original validation publication (13). On the other hand, no significant difference was found between the baseline and the retrospective pretreatment scores of these domains (including hypersomnolence). Interestingly, a high correlation was found between baseline and retrospective pretreatment scores in each domain.

It is interesting to elaborate on the factors that could account for the discrepant results obtained between baseline and retrospective values of the ESS and of the QSQ hypersomnolence domain scores. Obviously, it is exceedingly difficult to determine whether patients underestimated their ESS score before treatment and/or overestimated it retrospectively after treatment. One could hypothesize that the retrospective worsening of subjective baseline hypersomnolence observed with the ESS may be due to the insidious development of diurnal symptoms and to their long-term presence before diagnosis is made. Therefore, retrospective evaluation is based on the new condition that comes with the application of an effective treatment. In such cases, a similar retrospective worsening of diurnal symptoms should also be apparent with the QSQ hypersomnolence domain. The absence of such a finding suggests that this apparent discrepancy may relate to differences in questionnaire properties rather than patients' perception. First, the QSQ is an evaluative QoL questionnaire that quantifies hypersomnolence (in addition to other domains) using a global approach and not in the context of specific daytime conditions, as is the case with the ESS. Therefore, this domain's score provides an overview of diurnal sleepiness outside predetermined situations that may not encompass all daytime activities. Moreover, in the QSQ, hypersomnolence is evaluated through the responses to different questions that are not gathered for each specific domain but are randomly mixed with those of other domains. Therefore, when rating the importance of daytime vigilance impairment, the absence of aggregate questions regarding hypersomnolescence prevented any cross contamination between responses to questions that evaluated symptoms. This differs from the ESS, which also exhibits some redundancy, with internal validity improving when removing two of only eight questions (21). This could influence the scores provided by the two questionnaires because when completing the ESS, subjects can refer to the other items to rate their symptoms' perception and adjust their scores to each described situation.

The absence of differences in QoL scores perceived before and retrospectively after treatment was observed in each domain of the QSQ. This suggests that the questionnaire's topics and formulation adequately focused on complaints associated with OSA. We 
acknowledge that CPAP side effects could have interacted with the perceived benefits of treatment (ie, have you woken up often [more than twice] during the night, difficulty with a dry or sore mouth/ throat on awakening, difficulty returning to sleep if you wake up in the night?), thus interfering with the identification of changes after treatment and of differences between baseline and retrospective pretreatment scores. It would have been interesting to have a pretreatment test-retest of QSQ scores; however, for logistic reasons the pretreatment QSQ was not administered at the first visit at the clinic but later in the sleep apnea management process at the time the treatment discussion was held. However, it should be noted that the QSQ demonstrated an excellent test-retest reliability in our validation study (13).

\section{Clinical implications}

Even if the ESS score has been shown to fluctuate over time, clinicians often evaluate subjective symptoms only using the ESS. Kaminska et al (20) showed that the manner in which the ESS questionnaire is administered (physician versus self-administration) significantly influences the overall score. Interestingly, it was found that specific personality traits could account for $14 \%$ of variance of subjective daytime sleepiness of OSAS patients and influence the ESS score (21). Also, the ESS questions assessed diurnal sleepiness that can be influenced by other independent factors such as depression or obesity (22-24). Furthermore, it is firmly established that it is not possible to predict the presence of OSA based only on ESS score (25). Our results, combined with those of these other studies, illustrate the need to go beyond the ESS when evaluating vigilance impairment as part of the

\section{REFERENCES}

1. Douglas J. Disorders of the Respiratory System, Section 2 Diseases of the Respiratory System, Harrison's Online. Chapter 265 Sleep Apnea. Part 11

2. Flemons WW, Reimer MA. Development of a disease-specific health-related quality of life questionnaire for sleep apnea. Am J Respir Crit Care Med 1998;158:494-503.

3. Mazza S, Pépin JL, Naëgelé B, Plante J, Deschaux C, Lévy P. Most obstructive sleep apnoea patients exhibit vigilance and attention deficits on an extended battery of tests. Eur Respir J 2005;25:75-80.

4. Lattimore JD, Celermajer DS, Wilcox I. Obstructive sleep apnea and cardiovascular disease. J Am Coll Cardiol 2003;41:1429-37.

5. Basoglu OK, Sarac F, Sarac S, Uluer H, Yilmaz C. Metabolic syndrome, insulin resistance, fibrinogen, homocysteine, leptin, and C-reactive protein in obese patients with obstructive sleep apnea syndrome. Ann Thorac Med 2011;6:120-5.

6. Lacasse Y, Godbout C, Sériès F. Health-related quality of life in obstructive sleep apnoea. Eur Respir J 2002;19:499-503.

7. D'Ambrosio C, Bowman T, Mohsenin V. Quality of life in patients with obstructive sleep apnea: Effect of nasal continuous positive airway pressure - a prospective study. Chest 1999;115:123-9.

8. Avlonitou E, Kapsimalis F, Varouchakis G, Vardavas CI, Behrakis P. Adherence to CPAP therapy improves quality of life and reduces symptoms among obstructive sleep apnea syndrome patients. Sleep Breath 2011;16:563-9.

9. Rahaghi F, Basner RC. Delayed diagnosis of obstructive sleep apnea: Don't ask, don't tell. Sleep Breath 1999;3:119-24.

10. Mulgrew AT, Fox N, Ayas NT, Ryan CF. Diagnosis and initial management of obstructive sleep apnea without polysomnography: A randomized validation study. Ann Intern Med 2007;146:157-66.

11. Berry RB, Hill G, Thompson L, McLaurin V. Portable monitoring and autotitration versus polysomnography for the diagnosis and treatment of sleep apnea. Sleep 2008;31:1423-31.

12. Holmdahl C, Schöllin IL, Alton M, Nilsson K. CPAP treatment in obstructive sleep apnoea: A randomised, controlled trial of followup with a focus on patient satisfaction. Sleep Med 2009;10:869-74.

13. Lacasse Y, Bureau MP, Sériès F. A new standardised and selfadministered quality of life questionnaire specific to obstructive sleep apnoea. Thorax 2004;59:494-9.

14. Johns MW. A new method for measuring daytime sleepiness: The Epworth sleepiness scale. Sleep 1991;14:540-5. diagnosis of OSAS because the syndrome can be associated with poorly perceived hypersomnolence but with other nonspecific symptoms such as tiredness or depression. Although the discriminative properties of the ESS are useful for OSAS diagnosis, the present results support the potential benefits of adding other evaluative criteria to identify the presence of diurnal somnolence when sleep apnea is suspected, and also not to discard the need for a CPAP therapy trial in OSA patients with a normal baseline ESS. Such a recommendation is further supported by the fact that daytime hypersomnolence is accounted for in the determination of the risk associated with sleepdisordered breathing and for investigation/treatment priority.

\section{CONCLUSION}

The results of the present study demonstrate that OSA patients may underestimate their sleepiness according to the mostly widely used instrument to detect hypersomnolence. Such a finding may not be observed with other methods used to assess OSA-related symptoms, such as QoL questionnaires that also evaluate diurnal sleepiness. This suggests that other evaluative tools should be included in the evaluation of subjective daytime sleepiness in patients with suspected OSAS.

FUNDING: The study was supported by CIHR Grant 89985 .

DISCLOSURES: The authors have no financial disclosures or conflicts of interest to declare.

15. Ip S, D'Ambrosio C, Patel K, et al. Auto-titrating versus fixed continuous positive airway pressure for the treatment of obstructive sleep apnea: A systematic review with meta-analyses.

Syst Rev 2012;1:20.

16. Zimmermann C, Köhler D, Schönhofer B. Value of retrospective assessment of the Epworth Sleepiness Scale after long-term CPAP therapy in obstructive sleep apnea disorder. Pneumologie 2000;54:572-4. [In German]

17. Chin K, Fukuhara S, Takahashi K, et al. Response shift in perception of sleepiness in obstructive sleep apnea-hypopnea syndrome before and after treatment with nasal CPAP. Sleep 2004;27:490-3.

18. Nguyen AT, Baltzan MA, Small D, Wolkove N, Guillon S, Palayew M. Clinical reproducibility of the Epworth Sleepiness Scale. J Clin Sleep Med 2006;2:170-4.

19. Lee SJ, Kang HW, Lee LH. The relationship between the Epworth Sleepiness Scale and polysomnographic parameters in obstructive sleep apnea patients. Eur Arch Otorhinolaryngol 2011;269:1143-7.

20. Kaminska M, Jobin V, Mayer P, Amyot R, Perraton-Brillon M, Bellemare F. The Epworth Sleepiness Scale: Self-administration versus administration by the physician, and validation of a French version. Can Respir J 2010;17:e27-34.

21. Smith SS, Oei TP, Douglas JA, Brown I, Jorgensen G, Andrews J. Confirmatory factor analysis of the Epworth Sleepiness Scale (ESS) in patients with obstructive sleep apnoea. Sleep Med 2008;9:739-44.

22. Hayashida K, Inoue $Y$, Chiba S, et al. Factors influencing subjective sleepiness in patients with obstructive sleep apnea syndrome. Psychiatry Clin Neurosci 2007;61:558-63.

23. Pamidi S, Knutson KL, Ghods F, Mokhlesi B. Depressive symptoms and obesity as predictors of sleepiness and quality of life in patients with REM-related obstructive sleep apnea: Cross-sectional analysis of a large clinical population. Sleep Med 2011;12:827-31.

24. Basta M, Lin HM, Pejovic S, Sarrigiannidis A, Bixler E, Vgontzas AN. Lack of regular exercise, depression, and degree of apnea are predictors of excessive daytime sleepiness in patients with sleep apnea: Sex differences. J Clin Sleep Med 2008;4:19-25.

25. Bausmer U, Gouveris H, Selivanova O, Goepel B, Mann W. Correlation of the Epworth Sleepiness Scale with respiratory sleep parameters in patients with sleep-related breathing disorders and upper airway pathology. Eur Arch Otorhinolaryngol 2010;267:1645-8. 


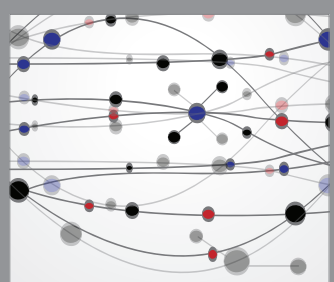

The Scientific World Journal
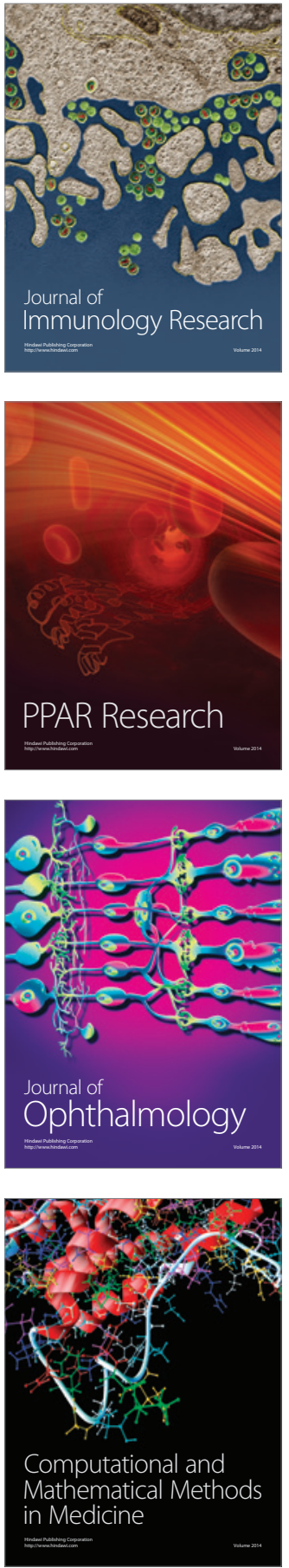

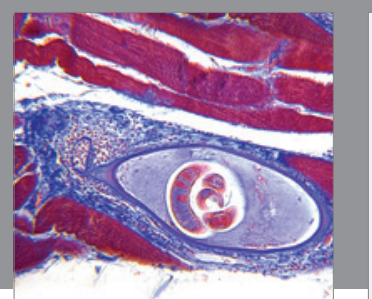

Gastroenterology Research and Practice

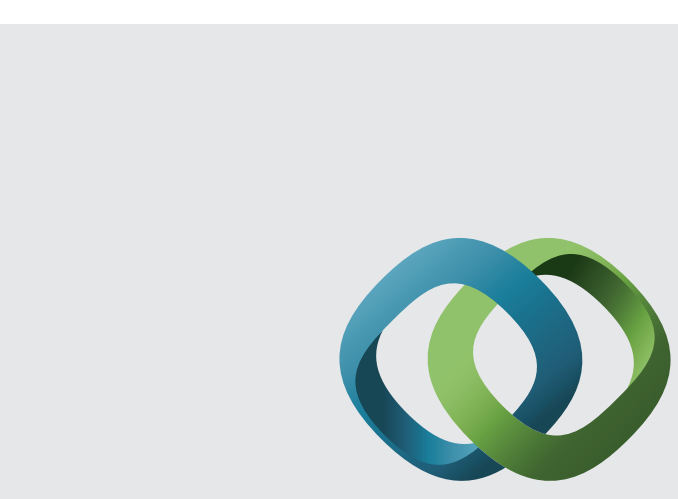

\section{Hindawi}

Submit your manuscripts at

http://www.hindawi.com
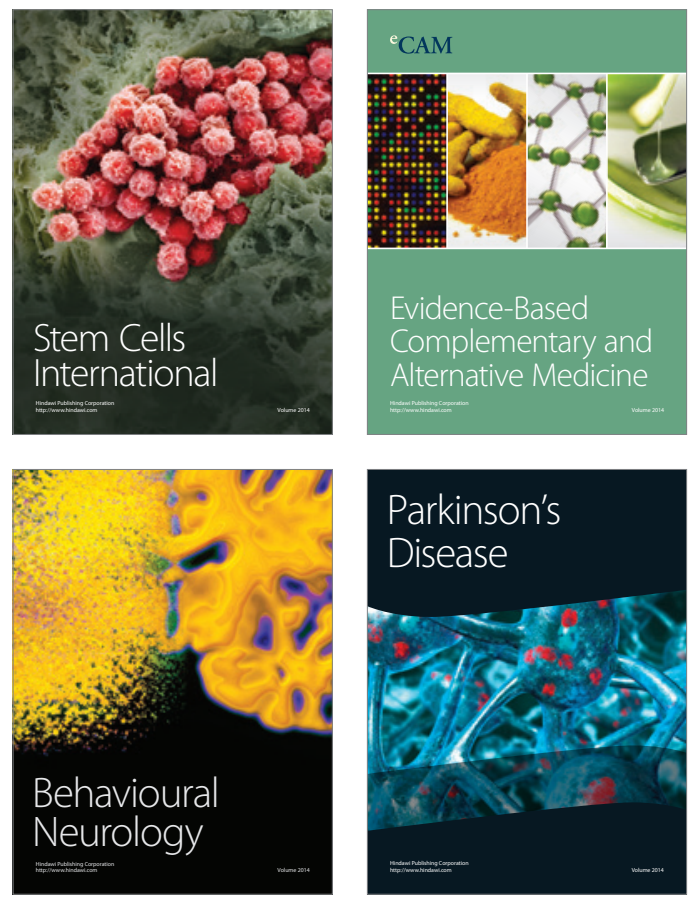
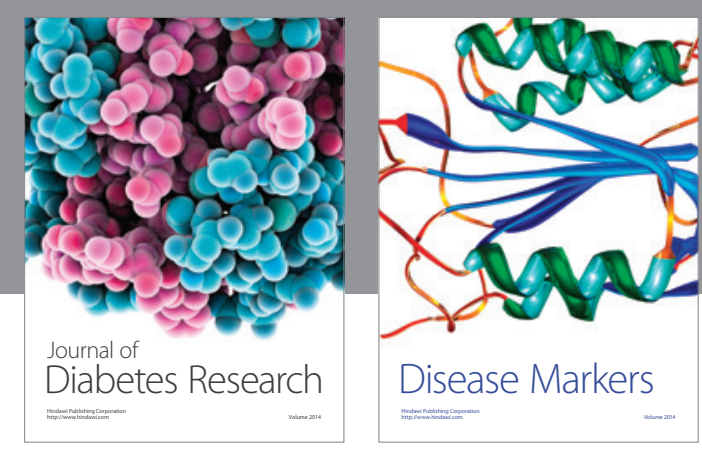

Disease Markers
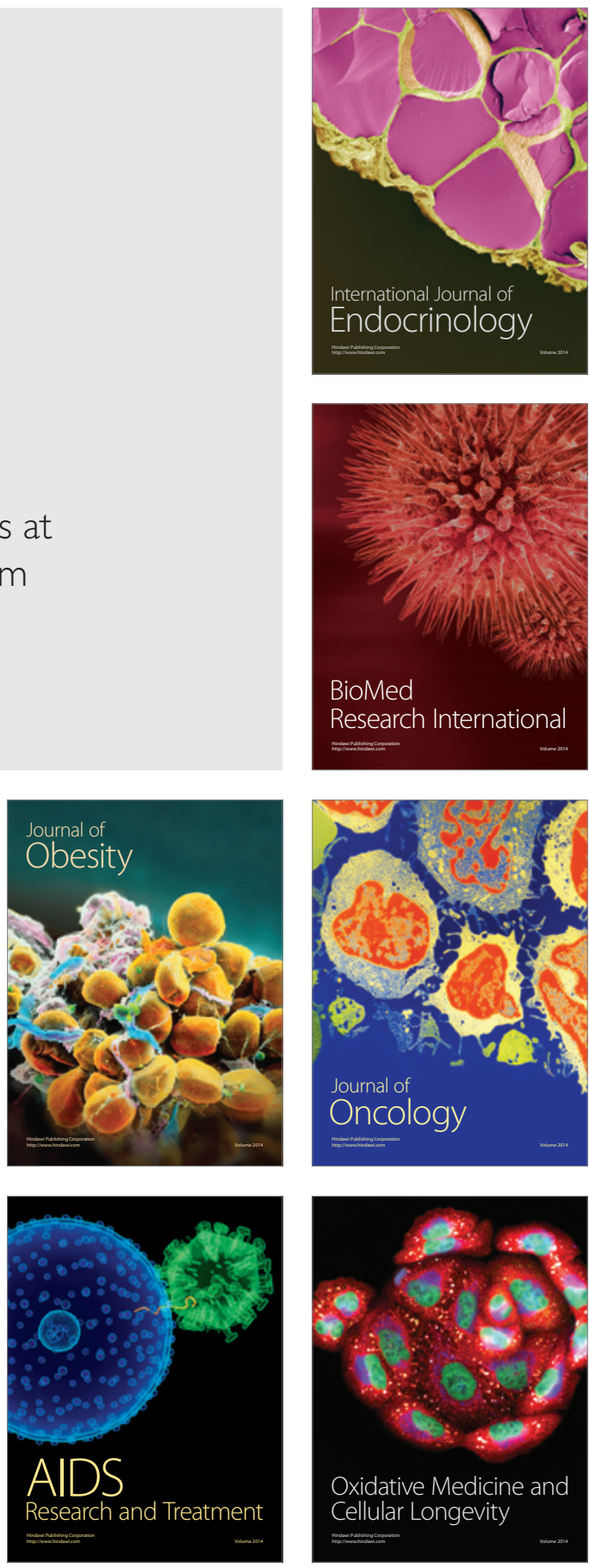